\title{
Effect of Carbonation on the Compressive Strength Development of Laterized Concrete
}

\author{
Samuel Olufemi FOLAGBADE \\ Department of Building, Obafemi Awolowo University, Ile-Ife 0220005, Nigeria
}

\begin{abstract}
Laterized concrete is characterised by decreasing compressive strength with increasing content of laterite. Carbonation, on the other hand, is noted to increase concrete strength. In order to reduce carbon dioxide from the atmosphere, this paper investigated the effect of carbonation on the compressive strength development of laterized concrete. The paper compared the compressive strengths of conventional and laterized concrete specimens containing up to $35 \%$ content of laterite cured in water for 126 days and in an accelerated carbonation chamber for 12 weeks at the water/cement ratios of $0.35,0.50$ and 0.65 . Results revealed that while the addition of laterite reduced compressive strength, carbonation increased the compressive strength development of laterized concrete. Furthermore, while equal strengths with water cured conventional concrete were achieved when laterite content is limited to $10 \%$, all the carbonated laterized concrete specimens achieved higher strengths than the water cured laterized concrete specimens at 12 weeks of accelerated carbonation. Hence, carbonation would enhance the strength development of laterized concrete, permit the use of higher content of laterite and contribute to the reduction of carbon dioxide from the atmosphere.
\end{abstract}

Keywords: carbonation, compressive strength, concrete, laterite, laterized concrete

DOI: $10.7176 / \mathrm{CER} / 12-4-04$

Publication date: April $30^{\text {th }} 2020$

\section{Introduction}

In order to reduce pressure on river sand and possibly reduce the cost of concrete, laterized concrete (a concrete in which the sand content has been partially replaced with laterite) has been suggested as an alternative to the conventional concrete (Lasisi \& Osunade, 1985; Falade, 1994; Udoeyo et al., 2006; Onipe \& Folagbade, 2017; Folagbade \& Osadola, 2019). However, the major shortcoming of laterized concrete is that the content of laterite should be limited to a level that would not impair its strength and durability performance. Hence, a laterite content of $20-40 \%$ have been suggested to ensure that laterized concrete would have good strength and durability performance (Onipe \& Folagbade, 2017; Folagbade \& Osadola, 2019). Also, to permit the use of higher contents of laterite, means of increasing the performance of laterized concrete at higher contents of laterite are required.

Greenhouse gases are released into the atmosphere through the burning of fossil fuels (oil, coal, wood, gas etc.) to provide energy for industrial use. Hence, the increasing level of industrialisation have created imbalance in the atmospheric level of carbon dioxide (the most dangerous of the greenhouse gases) resulting in health problems (respiratory diseases arising from air pollution) and environmental problems such as change in weather pattern (climate change) resulting in global warming, thermal discomfort, extinction problem, melting of ice, rising sea level and flooding. Also, the level of carbon dioxide in the atmosphere has been on the increase because the amount emitted by the various human activities outweighs the amount consumed by plants and oceans (Henson, 2008). The Kyoto Protocol and the move by the US, EU and China to meet the targeted emissions reduction levels have also failed (Torgal \& Jalali, 2011). According to the report of the Intergovernmental Panel on Climate Change, every sector of the global economy has contributed to the emissions and everyone is expected to devise means of preventing its devastation.

Cement manufacturing is noted to contribute significantly to emissions into the atmosphere (Worrell et al., 2001, Zhang et al., 2014). Hence, solutions like swapping fossil fuels with renewable sources, boosting energy efficiency, discouraging carbon dioxide emission by imposing climate change levy and the use of supplementary cementitious materials and alternative materials with lower embodied carbon dioxide contents to partly or fully replace the constituents of concrete have variously been suggested. However, all these solutions will only reduce the amount of carbon dioxide released into the atmosphere but not prevent the increase in the level of carbon dioxide in the atmosphere.

There is no doubting the fact that global warming will occur if the level of carbon dioxide in the atmosphere eventually exceeds the world carbon threshold. To prevent this from happening will require more than the aforementioned solutions. Hence, there is the need to vigorously pursue approaches, such as tree planting, conservation of existing forest and capturing of carbon dioxide generated by industries for further used.

A means of using carbon dioxide and preventing increase in its level in the atmosphere is carbonation of concrete. Carbonation occurs when carbon dioxide reacts with the products of hydration (especially calcium hydroxide $\left(\mathrm{Ca}(\mathrm{OH})_{2}\right)$ formed during the hydration reaction of Portland cement. Carbonation will deplete the passivating layer of $\mathrm{Ca}(\mathrm{OH})_{2}$ required to protect the embedded steel reinforcement against corrosion resulting in 
the spalling and degradation of concrete (Parrott, 1994, 1996; Jones et al., 2000). Hence, the service life of reinforced concrete would be affected by carbonation (Chi et al., 2002).

However, while carbonation could be detrimental to reinforced concrete, it will be beneficial to plain concrete precast or masonry units when used in the form of kerbs and interlocking blocks in road construction and blocks and bricks in wall construction. This is because carbonation would increase the compressive strength of concrete and refine its microstructure to improve its resistance to permeation (Parrott, 1987, Chi et al., 2002; Neville, 2012; Nakarai \& Yoshida, 2015). In order to improve the compressive strength of laterized concrete, encourage the use of higher contents of laterite in concrete and contribute to reducing the level of carbon dioxide in the atmosphere in order to make the environment friendlier, this paper investigated the effect of carbonation on the compressive strength development of laterized concrete.

\section{Materials and Methods}

The materials used in the experiment are ordinary Portland cement (Class 42.5), sand, laterite and granite chippings. Laterized concrete was produced at 5, 10, 15, 20, 25, 30 and 35\% contents of laterite. The properties of the aggregates are presented in Table 1 and illustrated in Figure 1.

Concrete was prepared to BS EN 12390-2 (2000), using mix proportions designed in accordance with the Building Research Establishment guide (Teychenne et al., 1997) and superplasticiser conforming to BS EN, at the water contents of $210 \mathrm{~kg} / \mathrm{m} 3$ and water/cement ratios of $0.35,0.50$ and 0.65 . Compressive strength test was carried out on water cured and carbonated $100 \mathrm{~mm}$ concrete cubes in accordance with BS EN 12390-3 (2002). Compressive strength was determined for water cured specimens at the curing ages of 28, 42, 70, 98 and 126 days.

The carbonated specimens were prepared in accordance with Dhir et al. (1989). The specimens were cured in water for 28 days and air cured for 14 days before being exposed to accelerated carbonation $\left(4 \% \mathrm{CO}_{2}\right.$ at the Relative Humidity of $50 \pm 5 \%$ ) at the curing age of 42 days for 4,8 and 12 weeks in the carbonation chamber. The exposure ages of 4, 8 and 12 weeks were respectively arranged to correspond to the water curing ages of 70 , 98 and 126 days. Hence, the compressive strength development of the water cured and carbonated concrete specimens were compared at the curing ages ranging between 28 and 128 days.

Table 1: Properties of aggregates

\begin{tabular}{lccc}
\hline & \multicolumn{2}{c}{ Fine aggregates } & Coarse aggregates \\
Properties & Laterite & Sand & 6.95 \\
\cline { 2 - 3 } Fineness modulus & 3.03 & 3.12 & 1.55 \\
Coefficient of uniformity & 5.23 & 3.24 & 0.90 \\
Coefficient of curvature & 0.99 & 0.96 & 2.70 \\
Specific gravity & 2.53 & 2.64 & 0.88 \\
Moisture content, \% & 7.33 & 5.17 & 1.58 \\
Absorption, \% & 9.15 & 1.09 & - \\
Liquid limit, \% & 37.0 & - & - \\
Plastic limit, \% & 17.0 & - & - \\
Plasticity index, \% & 20.0 & - & \\
\hline
\end{tabular}

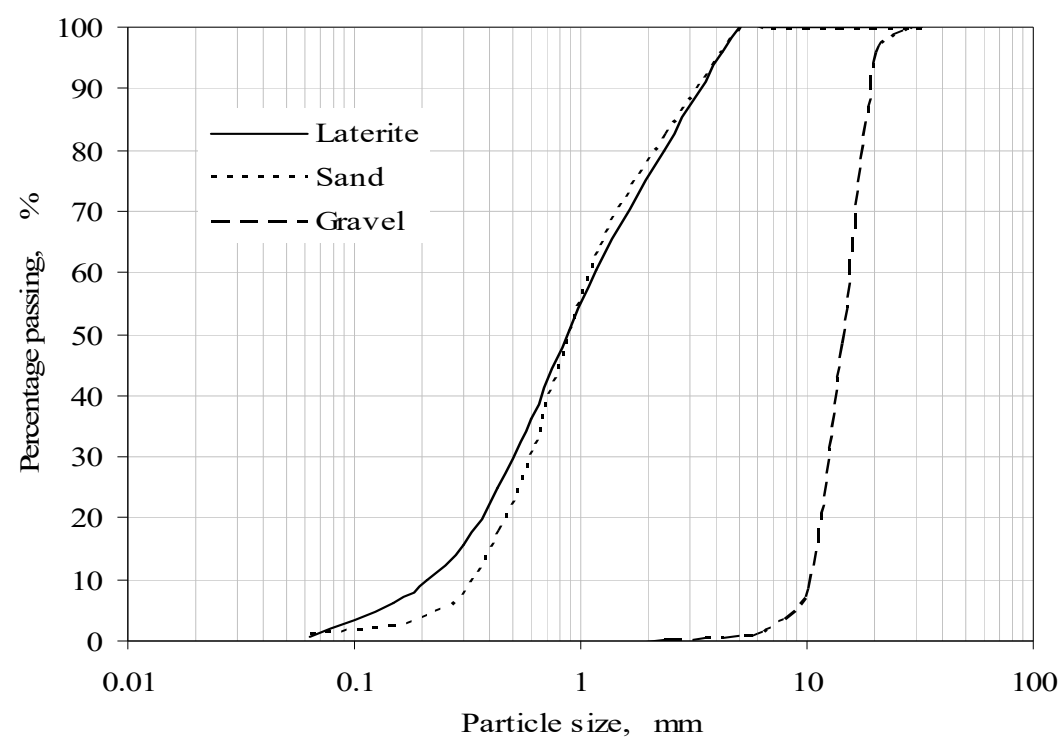

Figure 1: Grading curves of aggregates 


\section{Results and Discussion}

The compressive strengths of concretes cured in water and carbon dioxide at different contents of laterite at the curing ages of 28, 42, 70, 98 and 126 days at the water/cement ratios of $0.35,0.50$ and 0.65 are illustrated in Figures 2-4. The Figures show that the compressive strengths of the water cured and carbonated specimens reduced with increasing content of laterite. This is in line with previous studies by Folagbade (2018), Folagbade \& Aluko (2019) and Folagbade \& Osadola (2019). Also, while at each water/cement ratio and laterite content, compressive strength increased with increasing curing age from 28 to 126 days, the curvature of the curve shows a reduction in the strength development of the carbonated specimens between the ages of 28 and 42 days after which it picks up again. This is because the carbonated specimens were undergoing air drying (or air curing process) that should methodically precede the carbonation stage during this period. Since, at equal ages, compressive strength would be lower in air cured than water cured specimens (Mamlouk \& Zaniewski, 2006; James et al., 2011; Raheem et al., 2013), this observation is not unusual.
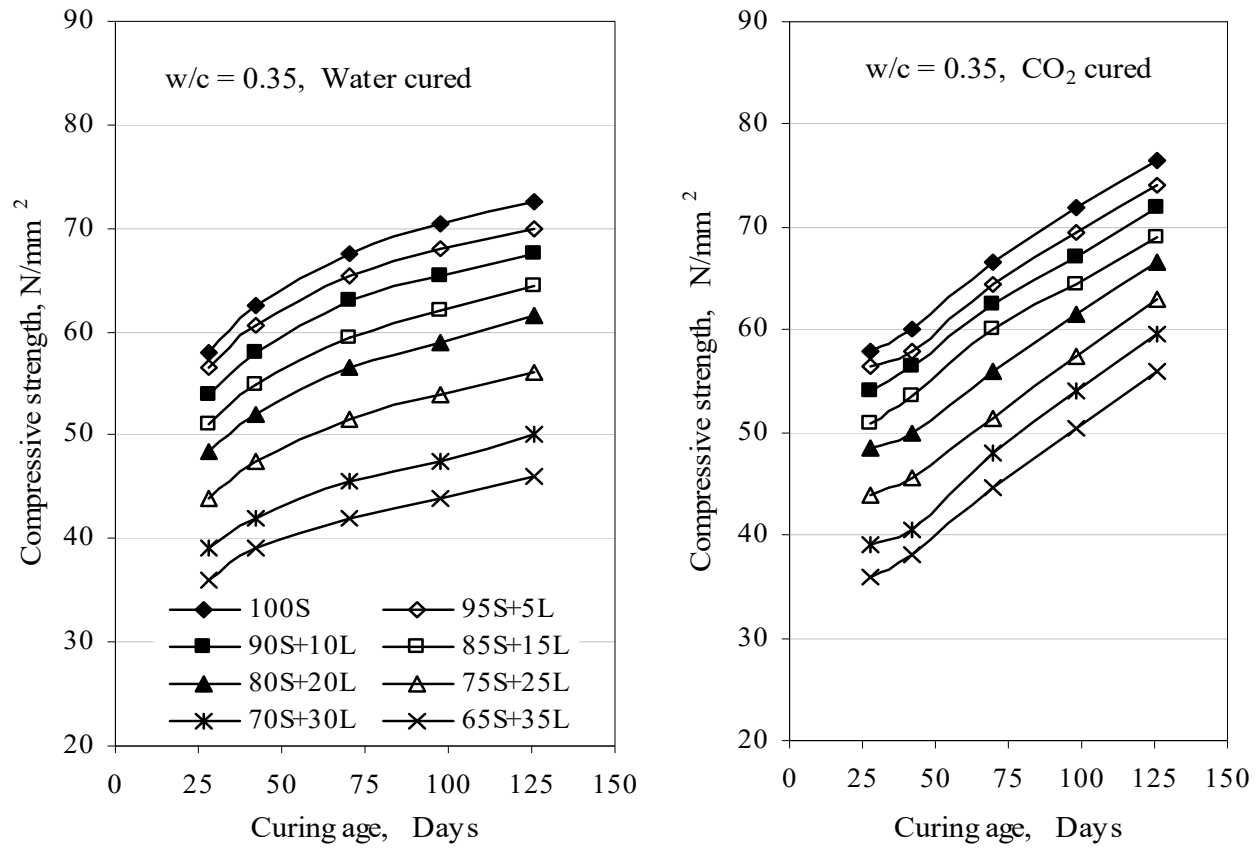

Figure 2: Compressive strength of concrete at the water/cement ratio of 0.35
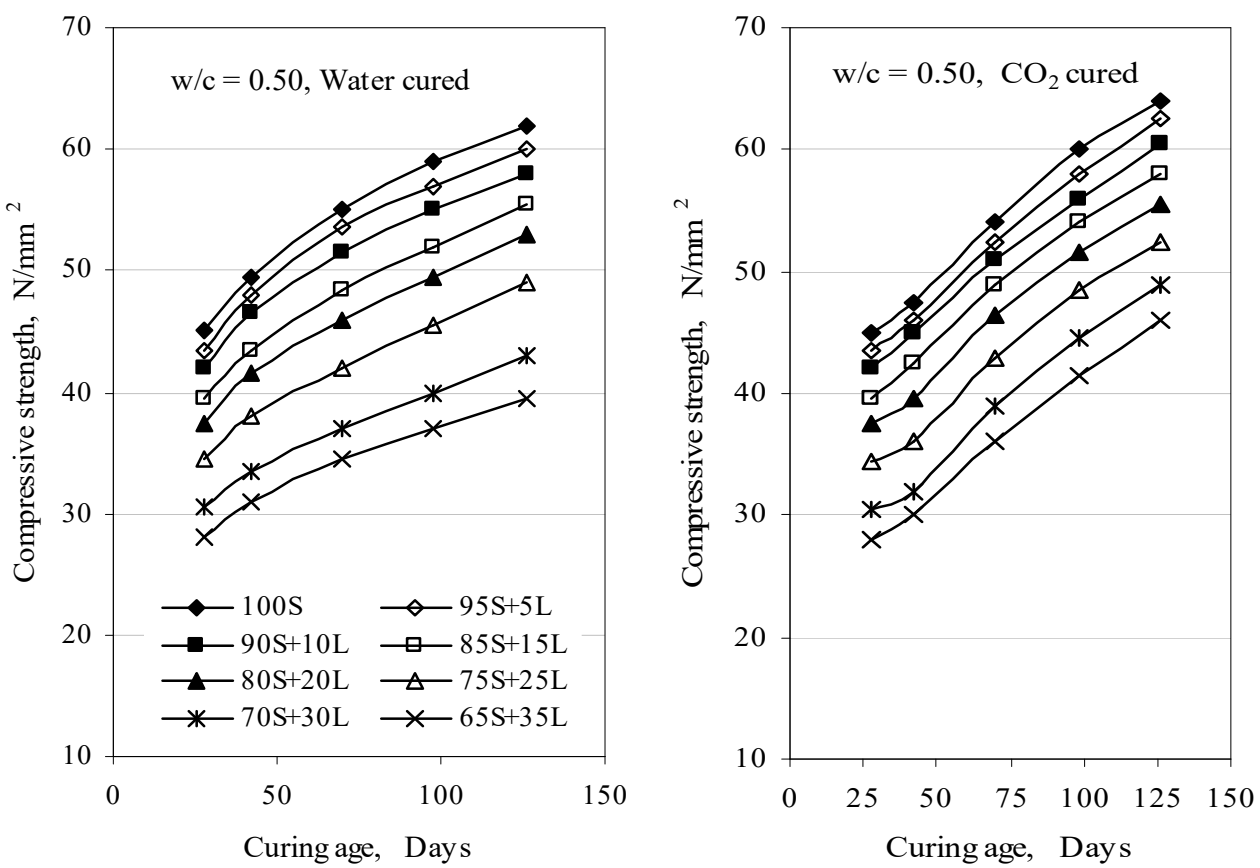

Figure 3: Compressive strength of concrete at the water/cement ratio of 0.50 

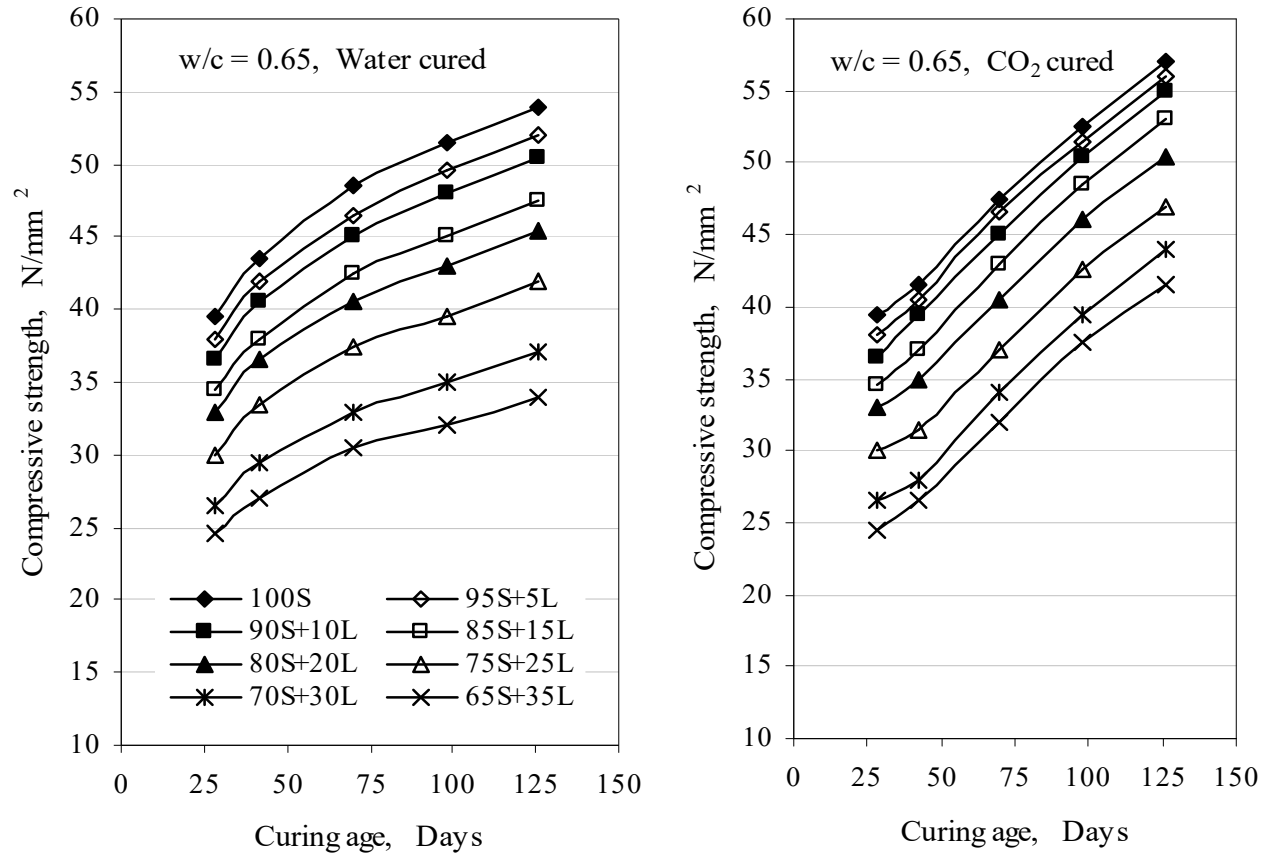

Figure 4: Compressive strength of concrete at the water/cement ratio of 0.65

Beyond the curing age of 42 days, the strength development of the carbonated specimens improved such that they have higher compressive strengths than the water cured specimens at equal contents of laterite at the curing age of 126 days. This shows that carbonation has the propensity to enhance the strength development of laterized concrete. This observation is supported by previous results by Chi et al. (2002) and Nakarai \& Yoshida (2015) which showed that carbonation would increase the compressive strength of concrete.

Table 2 compares the strength ratios of the water cured and carbonated concrete specimens at different contents of laterite, curing ages and water/cement ratios. The strength ratio is the ratio of the compressive strength of the carbonated concrete to that of the water cured specimens at equal contents of laterite. Compared with the wet cured specimens, the strength ratios of the carbonated specimens reduced from the curing age of 28 to 42 days. This also confirms the earlier observation that the strength development was lower in the carbonated specimens than the water cured specimens because the carbonated specimens were undergoing the air drying process and were yet to be introduced into the carbon chamber during this period.

Beyond 42 days, the strength ratios (and hence the rates of strength development) increased on exposure to accelerated carbonation such that mixes with more than $10 \%$ laterite contents achieved higher strengths than their corresponding water cured specimens after exposure to carbonation for four weeks. However, by the eighth week of exposure to carbonation and beyond, all the laterized concrete mixes achieved higher strengths than the wet cured specimens at equal laterite contents. Table 2 also shows that the beneficial effect of carbonation increased with increase in the content of laterite. This is probably due to the higher pore content associated with laterite than sand (Onipe \& Folagbade, 2017) permitting higher influx of carbon dioxide and therefore formation of higher content of calcium carbonate within the matrix of the concrete. 
Table 2: Strength ratios of concretes

\begin{tabular}{|c|c|c|c|c|c|c|c|}
\hline \multirow[t]{2}{*}{ Mix } & \multirow{2}{*}{$\begin{array}{l}\text { Curing } \\
\text { medium }\end{array}$} & \multirow[t]{2}{*}{$\mathrm{w} / \mathrm{c}$} & \multicolumn{5}{|c|}{ Strength ratio, $\%$} \\
\hline & & & $\mathrm{d} 28$ & $\mathrm{~d} 42$ & $\mathrm{~d} 70$ & d98 & d126 \\
\hline \multirow{6}{*}{$100 \mathrm{~S}$} & \multirow{3}{*}{ Water } & 0.35 & 100 & 100 & 100 & 100 & 100 \\
\hline & & 0.50 & 100 & 100 & 100 & 100 & 100 \\
\hline & & 0.65 & 100 & 100 & 100 & 100 & 100 \\
\hline & \multirow{3}{*}{$\mathrm{CO}_{2}$} & 0.35 & 100 & 96.00 & 98.52 & 102.13 & 105.52 \\
\hline & & 0.50 & 100 & 95.96 & 98.18 & 101.69 & 103.23 \\
\hline & & 0.65 & 100 & 95.40 & 97.94 & 101.94 & 105.56 \\
\hline \multirow{6}{*}{$95 \mathrm{~S}+5 \% \mathrm{~L}$} & \multirow{3}{*}{ Water } & 0.35 & 100 & 100 & 100 & 100 & 100 \\
\hline & & 0.50 & 100 & 100 & 100 & 100 & 100 \\
\hline & & 0.65 & 100 & 100 & 100 & 100 & 100 \\
\hline & \multirow{3}{*}{$\mathrm{CO}_{2}$} & 0.35 & 100 & 95.87 & 98.47 & 102.21 & 105.71 \\
\hline & & 0.50 & 100 & 95.83 & 98.13 & 101.75 & 104.17 \\
\hline & & 0.65 & 100 & 96.43 & 100 & 104.04 & 107.69 \\
\hline \multirow{6}{*}{$90 \mathrm{~S}+10 \mathrm{~L}$} & \multirow{3}{*}{ Water } & 0.35 & 100 & 100 & 100 & 100 & 100 \\
\hline & & 0.50 & 100 & 100 & 100 & 100 & 100 \\
\hline & & 0.65 & 100 & 100 & 100 & 100 & 100 \\
\hline & \multirow{3}{*}{$\mathrm{CO}_{2}$} & 0.35 & 100 & 97.41 & 99.21 & 102.29 & 106.67 \\
\hline & & 0.50 & 100 & 96.77 & 99.03 & 101.82 & 104.31 \\
\hline & & 0.65 & 100 & 97.53 & 100 & 105.21 & 108.91 \\
\hline \multirow{6}{*}{$85 \mathrm{~S}+15 \mathrm{~L}$} & \multirow{3}{*}{ Water } & 0.35 & 100 & 100 & 100 & 100 & 100 \\
\hline & & 0.50 & 100 & 100 & 100 & 100 & 100 \\
\hline & & 0.65 & 100 & 100 & 100 & 100 & 100 \\
\hline & \multirow{3}{*}{$\mathrm{CO}_{2}$} & 0.35 & 100 & 97.27 & 100.84 & 104.03 & 106.98 \\
\hline & & 0.50 & 100 & 97.70 & 101.03 & 103.85 & 104.50 \\
\hline & & 0.65 & 100 & 97.37 & 101.18 & 107.78 & 111.58 \\
\hline \multirow{6}{*}{$80 \mathrm{~S}+20 \mathrm{~L}$} & \multirow{3}{*}{ Water } & 0.35 & 100 & 100 & 100 & 100 & 100 \\
\hline & & 0.50 & 100 & 100 & 100 & 100 & 100 \\
\hline & & 0.65 & 100 & 100 & 100 & 100 & 100 \\
\hline & \multirow{3}{*}{$\mathrm{CO}_{2}$} & 0.35 & 100 & 96.15 & 99.12 & 104.24 & 108.13 \\
\hline & & 0.50 & 100 & 95.18 & 101.09 & 104.04 & 104.72 \\
\hline & & 0.65 & 100 & 95.89 & 100 & 106.98 & 110.99 \\
\hline
\end{tabular}

Table 2: Strength ratios of concretes contd.

\begin{tabular}{|c|c|c|c|c|c|c|c|}
\hline \multirow[t]{2}{*}{ Mix } & \multirow{2}{*}{$\begin{array}{l}\text { Curing } \\
\text { medium }\end{array}$} & \multirow[t]{2}{*}{$\mathrm{w} / \mathrm{c}$} & \multicolumn{5}{|c|}{ Strength ratio, $\%$} \\
\hline & & & $\mathrm{d} 28$ & $\mathrm{~d} 42$ & $\mathrm{~d} 70$ & d98 & $\mathrm{d} 126$ \\
\hline \multirow{6}{*}{$75 \mathrm{~S}+25 \mathrm{~L}$} & \multirow{3}{*}{ Water } & 0.35 & 100 & 100 & 100 & 100 & 100 \\
\hline & & 0.50 & 100 & 100 & 100 & 100 & 100 \\
\hline & & 0.65 & 100 & 100 & 100 & 100 & 100 \\
\hline & \multirow{3}{*}{$\mathrm{CO}_{2}$} & 0.35 & 100 & 95.79 & 100 & 106.48 & 112.50 \\
\hline & & 0.50 & 100 & 94.74 & 102.38 & 106.59 & 107.14 \\
\hline & & 0.65 & 100 & 94.03 & 98.67 & 107.59 & 111.90 \\
\hline \multirow{6}{*}{$70 \mathrm{~S}+30 \mathrm{~L}$} & \multirow{3}{*}{ Water } & 0.35 & 100 & 100 & 100 & 100 & 100 \\
\hline & & 0.50 & 100 & 100 & 100 & 100 & 100 \\
\hline & & 0.65 & 100 & 100 & 100 & 100 & 100 \\
\hline & \multirow{3}{*}{$\mathrm{CO}_{2}$} & 0.35 & 100 & 96.43 & 105.49 & 113.68 & 119.00 \\
\hline & & 0.50 & 100 & 95.52 & 105.41 & 111.25 & 113.95 \\
\hline & & 0.65 & 100 & 94.92 & 103.03 & 112.86 & 118.92 \\
\hline \multirow{6}{*}{$65 \mathrm{~S}+35 \mathrm{~L}$} & \multirow{3}{*}{ Water } & 0.35 & 100 & 100 & 100 & 100 & 100 \\
\hline & & 0.50 & 100 & 100 & 100 & 100 & 100 \\
\hline & & 0.65 & 100 & 100 & 100 & 100 & 100 \\
\hline & \multirow{3}{*}{$\mathrm{CO}_{2}$} & 0.35 & 100 & 97.44 & 105.95 & 114.77 & 121.74 \\
\hline & & 0.50 & 100 & 96.77 & 104.35 & 112.16 & 116.46 \\
\hline & & 0.65 & 100 & 98.15 & 104.92 & 117.19 & 122.06 \\
\hline
\end{tabular}

Table 3 presents the strength ratios and average strength disparities (over the water/cement ratios) of concrete specimens at the curing ages of 70,98 and 126 days (corresponding to the accelerated carbonation 
exposure ages of 4,8 and 12 weeks respectively). The Table shows that the compressive strength of the carbonated conventional concrete was higher than that of the water cured conventional concrete by an average of 1.92 and $4.77 \%$ at the exposure ages of 8 and 12 weeks respectively. This shows that carbonation would enhance the strength development of concrete. Furthermore, the strength disparities between the water cured conventional concrete and the carbonated laterized concrete reduced with increase in the exposure ages. This shows that carbonation has a positive effect on the compressive strength development of the laterized concrete.

Compared with the water cured conventional concrete, while the strength ratios of the laterized concrete mixes reduced with increasing content of laterite at equal curing age, the beneficial effect of carbonation increased with increasing curing age. Hence, equal or better compressive strengths than the water cured conventional concrete were achieved at the exposure age of 12 weeks by the carbonated laterized concrete specimens with not more than $10 \%$ laterite content. Also, carbonated laterized concrete specimens with up to $20 \%$ laterite contents achieved compressive strengths within $10 \%$ of the strength of the water cured conventional concrete.

Table 3: Strength ratios and strength disparities of concretes

\begin{tabular}{|c|c|c|c|c|c|c|c|c|c|c|}
\hline \multirow[t]{2}{*}{ Mix } & \multirow{2}{*}{$\begin{array}{l}\text { Curing } \\
\text { medium }\end{array}$} & \multirow[t]{2}{*}{$\mathrm{w} / \mathrm{c}$} & \multicolumn{5}{|c|}{ Strength ratio, $\%$} & \multicolumn{3}{|c|}{ Average strength disparity, $\%$} \\
\hline & & & $\mathrm{d} 28$ & $\mathrm{~d} 42$ & $\mathrm{~d} 70$ & d98 & $\mathrm{d} 126$ & $\mathrm{~d} 70$ & $\mathrm{~d} 98$ & $\mathrm{~d} 126$ \\
\hline \multirow{6}{*}{$100 \mathrm{~S}$} & \multirow{3}{*}{ Water } & 0.35 & 100 & 100 & 100 & 100 & 100 & \multirow{3}{*}{-} & \multirow{3}{*}{-} & \multirow{3}{*}{-} \\
\hline & & 0.50 & 100 & 100 & 100 & 100 & 100 & & & \\
\hline & & 0.65 & 100 & 100 & 100 & 100 & 100 & & & \\
\hline & \multirow{3}{*}{$\mathrm{CO}_{2}$} & 0.35 & 100 & 96.00 & 98.52 & 102.13 & 105.52 & \multirow{3}{*}{-1.79} & \multirow{3}{*}{+1.92} & \multirow{3}{*}{+4.77} \\
\hline & & 0.50 & 100 & 95.96 & 98.18 & 101.69 & 103.23 & & & \\
\hline & & 0.65 & 100 & 95.40 & 97.94 & 101.94 & 105.56 & & & \\
\hline \multirow{3}{*}{$\begin{array}{c}95 \mathrm{~S} \\
+ \\
5 \mathrm{~L} \\
\end{array}$} & \multirow{3}{*}{$\mathrm{CO}_{2}$} & 0.35 & 97.41 & 92.80 & 95.56 & 98.58 & 102.07 & \multirow{3}{*}{-4.37} & \multirow{3}{*}{-1.04} & \multirow{3}{*}{+2.19} \\
\hline & & 0.50 & 96.67 & 92.93 & 95.45 & 98.31 & 100.81 & & & \\
\hline & & 0.65 & 96.20 & 93.10 & 95.88 & 100.00 & 103.70 & & & \\
\hline \multirow{3}{*}{$\begin{array}{c}90 \mathrm{~S} \\
+ \\
10 \mathrm{~L} \\
\end{array}$} & \multirow{3}{*}{$\mathrm{CO}_{2}$} & 0.35 & 93.10 & 90.40 & 92.59 & 95.04 & 99.31 & \multirow{3}{*}{-7.30} & \multirow{3}{*}{-3.99} & \multirow{3}{*}{-0.42} \\
\hline & & 0.50 & 93.33 & 90.91 & 92.73 & 94.92 & 97.58 & & & \\
\hline & & 0.65 & 92.41 & 90.80 & 92.78 & 98.06 & 101.85 & & & \\
\hline \multirow{3}{*}{$\begin{array}{c}85 \mathrm{~S} \\
+ \\
15 \mathrm{~L}\end{array}$} & \multirow{3}{*}{$\mathrm{CO}_{2}$} & 0.35 & 87.93 & 85.60 & 88.89 & 91.50 & 95.17 & \multirow{3}{*}{-11.12} & \multirow{3}{*}{-7.60} & \multirow{3}{*}{-4.38} \\
\hline & & 0.50 & 87.78 & 85.86 & 89.09 & 91.53 & 93.55 & & & \\
\hline & & 0.65 & 87.34 & 85.06 & 88.66 & 94.17 & 98.15 & & & \\
\hline & & 0.35 & 83.62 & 80.00 & 82.96 & 87.23 & 91.72 & & & \\
\hline+ & $\mathrm{CO}_{2}$ & 0.50 & 83.33 & 79.80 & 84.55 & 87.29 & 89.52 & -16.33 & -12.05 & -8.41 \\
\hline $20 \mathrm{~L}$ & & 0.65 & 83.54 & 80.46 & 83.51 & 89.32 & 93.52 & & & \\
\hline $75 S$ & & 0.35 & 75.86 & 72.80 & 76.30 & 81.56 & 86.90 & & & \\
\hline+ & $\mathrm{CO}_{2}$ & 0.50 & 76.67 & 72.73 & 78.18 & 82.20 & 84.68 & -23.08 & -17.91 & -13.79 \\
\hline $25 \mathrm{~L}$ & & 0.65 & 75.95 & 72.41 & 76.29 & 82.52 & 87.04 & & & \\
\hline $70 \mathrm{~S}$ & & 0.35 & 67.24 & 64.80 & 71.11 & 76.60 & 82.07 & & & \\
\hline+ & $\mathrm{CO}_{2}$ & 0.50 & 67.78 & 64.65 & 70.91 & 75.42 & 79.03 & -29.29 & -23.76 & -19.14 \\
\hline $30 \mathrm{~L}$ & & 0.65 & 67.01 & 64.37 & 70.10 & 76.70 & 81.48 & & & \\
\hline $65 \mathrm{~S}$ & & 0.35 & 62.07 & 60.80 & 65.93 & 71.63 & 77.24 & & & \\
\hline+ & $\mathrm{CO}_{2}$ & 0.50 & 62.22 & 60.61 & 65.45 & 70.34 & 74.19 & -34.21 & -28.40 & -23.91 \\
\hline $35 \mathrm{~L}$ & & 0.65 & 62.03 & 60.92 & 65.98 & 72.82 & 76.85 & & & \\
\hline
\end{tabular}

\section{Conclusion}

This paper investigated the effect of carbonation on the compressive strength development of laterized concrete and the following conclusions have been drawn.

- Compressive strength reduced with increasing content of laterite and increased with increasing curing in water and carbon dioxide.

- At equal laterite content, the rate of strength development of laterized concrete would be higher when carbonated than when water cured.

- With carbonation, laterized concretes with compressive strengths better or comparable to that of the conventional concrete is possible.

The study therefore concludes that carbonation would increase the compressive strength development of laterized concrete and helps in the removal of carbon dioxide from the atmosphere.

\section{References}

BS EN 12390- 2 (2000). Testing hardened concrete- Part 2: Making and curing specimens for strength tests. 
London: British Standards Institution.

BS EN 12390- 3 (2002). Testing hardened concrete- Part 3: Compressive strength of test specimens. London: British Standards Institution.

Chi, J. M., Huang, R., \& Yang, C. C. (2002). Effects of carbonation on mechanical properties and durability of concrete using accelerated testing methods. Journal of Marine Science and Technology, 10(1), 14-20.

Dhir R K., Hewlett P.C. \& Chan Y. N., 1989, Near surface characteristics of concrete: Intrinsic permeability, Magazine of Concrete Research, 41 (147), 87-97.

Folagbade, S. O. and Aluko O. (2019): Permeation Resistance of Sawdust Ash Blended Cement Laterized Concrete. Civil Engineering Dimension, 21(2), 76-83.

Folagbade, S. O. and Osadola O. A. (2019): Workability, Compressive Strength and Initial Surface Absorption of Laterized Concrete. Journal of Materials and Engineering Structures, 6(3), 455-463.

Henson R., 2008, The Rough guide to climate change, Rough Guides, London.

James, T., Malachi, A., Gadzama, E. W. \& Anametemfiok V. (2011). Effect of curing methods on the compressive strength of concrete. Nigerian Journal of Technology, 30(3), 14-20.

Jones, M. R., Dhir, R. K., Newlands, M. D. and Abbas, A. M. O. (2000). Study of the CEN Test Method for measurement of the carbonation depth of hardened concrete. Materials and Structures, 33 (226), 135-142.

Mamlouk, M. S. \& Zaniewski, J. P. (2006). Materials for Civil and Construction Engineers, 2nd Edition. New Jersey: Pearson Prentice Hall.

Nakarai, K., \& Yoshida, T. (2015). Effect of carbonation on strength development of cement-treated toyoura silica sand. Soils and Foundations, 55(4), 857-865.

Neville, A. M. (2012). Properties of Concrete. London: Prentice Hall.

Onipe, M. O. and Folagbade, S. O. (2017): Void Content and Sorptivity of Laterized Concrete. In Aluko B. T., Odeyinka H. A., Amole O. O., Babasehinde A. A. and Daramola O. P. (eds.), Proceedings of the Environmental Design and Management International Conference on Advances in Built Environment Research-Recent Advances and Future Directions, 159-168, 22-24 May, Obafemi Awolowo University, Ile-Ife, Nigeria.

Parrott L. J. (1994). A study of carbonation-induced corrosion. Magazine of Concrete Research, 46 (166), 23-28.

Parrott L. J. (1996). Some effects of cement and curing upon carbonation and reinforcement corrosion in concrete. Materials and Structures, 29 (187), 164-173.

Raheem, A. A., Soyingbe, A. A. \& Emenike, A. J. (2013). Effect of curing methods on density and compressive strength of concrete. International Journal of Applied Science and Technology, 3(3), 55-64.

Soon, W., Baliunas, S. L., Robinson, A. B., \& Robinson, Z. W. (1999). Environmental effects of increased atmospheric carbon dioxide. Climate Research, 13, 149-164.

Teychenne, D. C., Franklin, R. E. \& Erntroy H. C. (1997). Design of Normal Concrete Mixes, 2nd Edition. Amended by B. K. Marsh, Building Research Establishment.

Torgal, F. P., \& Jalali, S. (2011). Eco-efficient construction and Building Materials. London: Springer.

Worrell, E., Price, L., Martin, N., Hendriks, C. \& Meida, L. O. (2001). Carbon-dioxide emissions from the global cement industry, Annual Review of Energy and the Environment, 26, 303-329.

Zhang, J., Liu, G., Chen, B., Song, D., Qi, J., \& Liu, X. (2014). Analusis of CO2 emission for the cement manufacturing with alternative raw materials: A LCA-based framework. Energy Procedia, 61, 2541-2545. 